\title{
Specific strength training compared with interdisciplinary counseling for girls with tension-type headache: a randomized controlled trial
}

\author{
This article was published in the following Dove Press journal: \\ Journal of Pain Research \\ 4 May 2016 \\ Number of times this article has been viewed
}

\section{Birte Tornøe ${ }^{1-4}$ \\ Lars L Andersen ${ }^{5,6}$ \\ Jørgen H Skotte ${ }^{5}$ \\ Rigmor Jensen ${ }^{7}$ \\ Claus Jensen ${ }^{8}$ \\ Bjarne K Madsen ${ }^{7}$ \\ Gunvor Gard' \\ Liselotte Skov ${ }^{2}$ \\ Inger Hallström'}

'Department of Health Sciences, Lund University, Lund, Sweden; ' ${ }^{2}$ Department of Pediatrics E, Children's Headache Clinic, University of Copenhagen, Herlev and Gentofte Hospitals, Copenhagen, Denmark; ${ }^{3}$ Department of Physiotherapy and Occupational Therapy, University of Copenhagen, Glostrup Hospital, Copenhagen, Denmark; ${ }^{4}$ Department of Physiotherapy, University of Copenhagen, Herlev and Gentofte Hospitals, Copenhagen, Denmark; ${ }^{5}$ National Research Centre for the Working Environment, Copenhagen, Denmark; ${ }^{6}$ Physical Activity and Human Performance group, SMI, Department of Health Science and Technology, Aalborg University, Aalborg, Denmark; ' Department of Neurology, Danish Headache Centre, University of Copenhagen, Glostrup Hospital, Copenhagen, Denmark; ${ }^{8}$ Huge Consulting, ApS, Haslev, Denmark

Correspondence: Birte Tornøe Department of Pediatrics E, Children's Headache Clinic, University of Copenhagen, Herlev Hospital, Herlev Ringvej 75, 2730 Herlev, Copenhagen, Denmark

Tel +453868 1067

Email birte.tornoee@regionh.dk
Background: Childhood tension-type headache (TTH) is a prevalent and debilitating condition for the child and family. Low-cost nonpharmacological treatments are usually the first choice of professionals and parents. This study examined the outcomes of specific strength training for girls with TTH.

Methods: Forty-nine girls aged 9-18 years with TTH were randomized to patient education programs with 10 weeks of strength training and compared with those who were counseled by a nurse and physical therapist. Primary outcomes were headache frequency, intensity, and duration; secondary outcomes were neck-shoulder muscle strength, aerobic power, and pericranial tenderness, measured at baseline, after 10 weeks intervention, and at 12 weeks follow-up. Healthrelated quality of life (HRQOL) questionnaires were assessed at baseline and after 24 months.

Results: For both groups, headache frequency decreased significantly, $P=0.001$, as did duration, $P=0.022$, with no significant between-group differences. The odds of having headache on a random day decreased over the 22 weeks by $0.65(0.50-0.84)$ (odds ratio [ $95 \%$ confidence interval]). For both groups, neck extension strength decreased significantly with a decrease in cervicothoracic extension/flexion ratio to 1.7 , indicating a positive change in muscle balance. In the training group, shoulder strength increased $\geq 10 \%$ in $5 / 20$ girls and predicted $V \mathrm{O}_{2_{\max }}$ increased $\geq 15 \%$ for $4 / 20$ girls. In the training group, $50 \%$ of girls with a headache reduction of $\geq 30 \%$ had an increase in $V \mathrm{O}_{2}>5 \%$. For the counseling group, this was the case for $29 \%$. A 24-month follow-up on HRQOL for the pooled sample revealed statistically significant improvements. Fifty-five percent of the girls reported little to none disability.

Conclusion: The results indicate that both physical health and HRQOL can be influenced significantly by physical exercise and nurse counseling. More research is needed to examine the relationship between physical exercise, $V \mathrm{O}_{2_{\max }}$, and TTH in girls. Thus, empowering patient education to promote maximum possible outcomes for all children needs more attention.

Keywords: empowering patient education, neck and shoulder muscles, muscular fitness, cardiovascular fitness, headache, child, health and physical therapy

\section{Introduction}

Frequent episodic and chronic childhood tension-type headache (TTH) is a prevalent and debilitating situation for the child and family. After clarifying the diagnosis in an interdisciplinary setting, nonpharmacological treatments are usually the first choice of professionals and parents. Because many parents are reluctant to choose preventive medication for their child, patient education is an important aspect of pediatric headache team 
services. The focus is on empowering the family to incorporate a healthy lifestyle at home and at school to actively prevent the development or triggering of headache. The most basic lifestyle factors that a discussion (between nurse/physical therapist and parent) can contribute to are sufficiency of sleep, liquids, food, activity level, and how to handle psychosocial stressors. ${ }^{1}$

For nonpharmacological behavioral treatments, patient education on relaxation therapy with or without electromyographic or thermal biofeedback has shown, over the last 20 years, substantial evidence in reducing headache frequency in both children and adults. ${ }^{2-5}$ Passive acupunctural laser therapy has also shown positive effects in a controlled trial on headache frequency. ${ }^{6}$ Andrasik et $\mathrm{al}^{7}$ compared preventive medication with amitriptyline and relaxation therapy for juvenile TTH and found clinical improvements from both interventions at 1- and 2-year follow-up. Relaxation therapy showed better compliance and acceptance by parents. Even though these effects are supported by evidence, use in practice is more limited than expected. ${ }^{8} \mathrm{~A}$ major limitation is that interventions such as relaxation therapy require approximately up to ten 1-hour sessions in which a trained expert teaches the child with the use of specialized equipment. ${ }^{8}$ As families are busy and society resources sparse, there is a need for educational approaches that are not only less costly but also more accessible and flexible, which is why internet-based self-help interventions are on the rise; ${ }^{9}$ other alternatives are warranted.

Physical training compared to relaxation therapy and acupuncture has been examined in one study for adults with chronic TTH. ${ }^{10}$ Within-group differences showed significant positive long-lasting effects for all three treatments. Moderate physical training showed significant reductions in headache frequency and intensity. Brief daily strength training using elastic bands has also been shown to reduce nonchronic headache frequency in adult office workers with neck-shoulder muscle pain. ${ }^{11}$ Physical exercise for children has not yet been examined, although the World Health Organization published Global Recommendations on Physical Activity for Health in 2011 specifically for children aged 5-17. ${ }^{12}$ In one of our previous studies, we found reduced neck-shoulder muscle strength and aerobic power together with increased pericranial tenderness, especially in the trapezius descendens, to be associated with TTH in girls. ${ }^{13}$ We hypothesized that strengthening the shoulder muscles would result in reduced headache frequency and improvements in the girl's physical capabilities. This study aimed at comparing the outcomes of specific supervised strength training of shoulder muscles with the outcomes of counseling (defined patient education programs) for girls with TTH.

\section{Methods \\ Design}

A randomized controlled trial was performed in accordance with the CONSORT 2010 Statement $^{14}$ and guidelines for trials for recurrent headache. ${ }^{15,16}$ The trial was approved by The National Committee on Health Research Ethics for Hospitals in the Capital Region of Denmark, and the Danish Data Protection Agency. Registered by ClinicalTrials.gov H-3-2009-081, identifier NCTO115557.

\section{Participants}

From May 1, 2010 to September 1, 2013, 49 consecutive girls aged 9-18 years agreed to participate in the study with a 24-months follow-up period until September 2015. They were diagnosed exclusively with either frequent episodic TTH (at least ten episodes, $\geq 1$ day but $<15$ days per month for at least 3 months) or chronic TTH ( $\geq 15$ days per month on average for $>3$ months), thus fulfilling the International Classification of Headache Disorders 2nd Edition and 3rd Edition, beta version. ${ }^{17,18}$ We were unable to recruit a sufficient number of boys to meet the criteria for statistical analyses.

All participants were diagnosed and recruited from the Children's Headache Clinic, Glostrup and Herlev Hospitals, University of Copenhagen. Before inclusion, the girls with TTH underwent a clinical diagnostic and neurological examination that included examination of the spine by the department's neuropediatricians and one specialist physical therapist. The diagnosis was clarified using 1- to 6-month headache reports from a diary similar to that recommended by Jensen et al. ${ }^{19}$ Exclusion criteria were set by the neuropediatrician from anamnestic, observational and clinical assessments. Exclusion criteria were: migraine headache with more than one episode per month for a period of 6 months; a history of trauma, arterial hypertension, or intracranial hypertension; headache secondary to a cervical or other morbidity; and headache associated with a psychiatric comorbidity. Another exclusion criterion was headache associated with a significant learning disability or complicated social situation that required special education and/or community involvement. Girls who had been or were enrolled in other treatment programs at the Children's Headache Clinic were also excluded. No preventive headache medication and/or analgesic overuse were allowed before or during the study period. None of the participants were allowed the intake of analgesics, taken for any reason, within 12 hours before testing. At the first diagnostic visit, all participants were informed by the contact physician and nurse about the basic needs a child has for adequate food, 
liquids, sleep, and activity. Figure 1 depicts a flow diagram of the study enrollment and allocation.

This study followed the ethical principles of the World Medical Association's Declaration of Helsinki 2008 and $2013^{20}$ and the United Nations Convention on the Rights of the Child 1989. ${ }^{21}$ The parents gave written informed consent, and the children gave oral informed assent. According to the ethical guidelines, children above the age of 15 also received special age-appropriate information. Participants were informed about confidentiality and the right to withdraw from the study at any time without affecting their treatment.

\section{Self-reports}

Self-reports of headache were monitored daily using a visual analog score (VAS)/numeric scale ${ }^{22}$ in a monthly calendar. Mean headache frequency, intensity, and duration over 28 days prior to the test date were calculated.
Health-related quality of life (HRQOL) and disability were recorded at baseline and were administered by a nurse during the first visit at the clinic for counseling and diagnosis. A follow-up was administered by means of a mailed questionnaire 24 months after baseline.

1. Self-reports of the Pediatric Quality of Life Inventory (PedsQL $^{\text {тм }}$ 4.0; Mapi Research Institute, Lyon, France) Generic Core Scales. Validated and validated in translation to Danish, ${ }^{23}$ the questionnaire consists of 23 items comprising four dimensions: physical functioning (eight items), emotional functioning (five items), social functioning (five items), and school functioning (five items), which were scored on a five-point Likert scale ( 0 - 4/neveralmost always). Parental and child reports were collected for children aged 8-12 and 13-18 years. ${ }^{24}$ For data analysis, raw scores $0-4$ were reciprocally transformed to $0-100$ scale scores following the scoring instructions. ${ }^{25}$

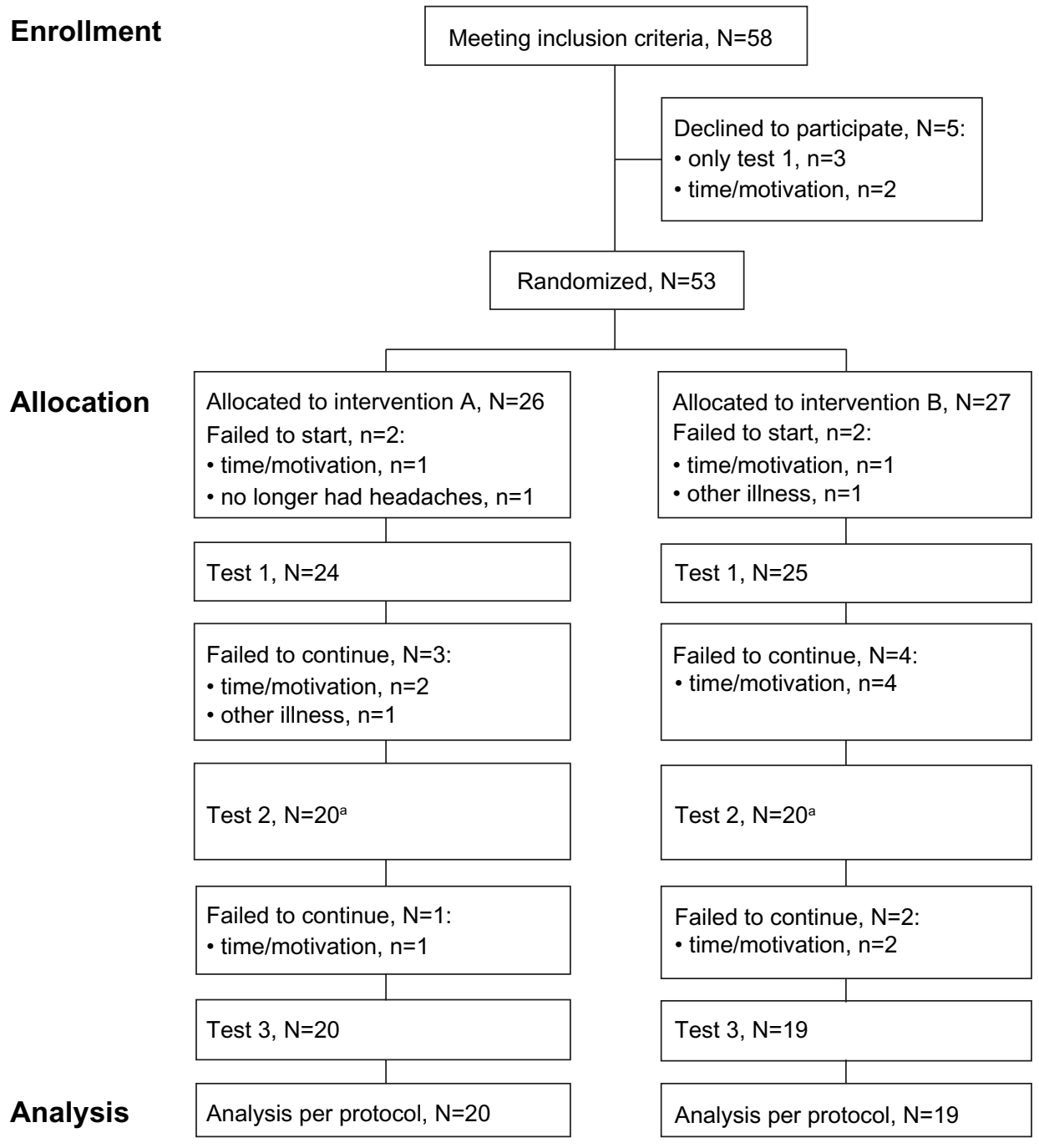

Figure I Flow diagram of enrollment and allocation.

Note: ane participant was sick at test 2 and therefore data for this participant is missing. The participant reentered at test 3. 
2. Self-reports of the Pediatric Migraine Disability Assessment (PedMIDAS) questionnaire translated into Danish. The first three PedMIDAS questions relate to the impact of headache on school attendance and performance. The fourth question concerns the disability at home. The final two questions relate to social and physical functioning. The score is a simple composite of the six questions. Originally developed to assess migraine disability in pediatric and adolescent patients, PedMIDAS has been tested and validated for 4-18-year-olds with migraine by the Cincinnati Children's Headache Centre ${ }^{26,27}$ and it also addresses children with TTH. ${ }^{28}$ The score is interpreted as follows: 0-10 little to none disability grade; 11-30 Grade II, mild; 31-50 Grade III, moderate; and above 50 Grade IV, severe disability.

\section{Test procedures and measurements}

Measurements were conducted at baseline, after 10 weeks of intervention and after 12 weeks of home practice/follow-up; in all 22 weeks. A bioanalytic research assistant, blinded to the participants' histories, trained and experienced in the specific test methods, conducted the testing. The participants were given detailed information to familiarize themselves with the procedure. A coassistant, also blinded, assisted the child during the test procedures. The test procedures followed a standardized protocol and were conducted in a warm comfortable room. Test procedures lasted approximately 1 hour. The child was provided a bottle of water during testing and fruit afterwards.

1. Age and anthropometric measures such as height and weight were collected. Body mass index (BMI) was calculated.

2. General joint mobility was screened using the validated Beighton Score with nine points as a maximum. The cut-off for positive findings of hypermobility was 5/9. ${ }^{29}$

3. Tenderness of pericranial muscles was examined in a sitting position in a chair with adjustable neck and leg support using the Total Tenderness Score (TTS) system validated by Bendtsen et al. ${ }^{30,31}$ A total score was calculated based on the standardized manual palpation procedures of seven bilateral sites (masseter, frontalis, temporalis, processus mastoideus, occipital insertion, trapezius, and sternocleidomastoideus) using a four-point scale. The maximum possible score was 42 points.

4. Isometric muscular testing was conducted using a computerized force transducer, model Vishay Nobel, type KIS-2, max. 2 kN (Vishay Precision Group, Malvern, PA, USA) wall mounted on a custom-built adjustable stand.
The signal from the force transducer was amplified and sampled in the computer using a National Instruments, type PWR02 (including a strain gauge amplifier, type SCC-SG24), and a data acquisition card Daqcard-6036E (National Instruments, Austin, TX, USA). All signals were sampled with a frequency of $100 \mathrm{~Hz}$ and low-pass filtered with a cut-off frequency of $10 \mathrm{~Hz}$. The child was positioned on a chair with the upper and lower trunk fixed with belts.

For neck flexion measurements, the lower edge of the padded force transducer was positioned to correspond with the line between the eyebrows. For neck extension measurements, the pad was positioned with the lower edge corresponding with the protuberantia occipitalis. The testing included isometric maximal voluntary contraction (MVC) in neck flexion and extension from a neutral upright position. The child was instructed to slowly build up the force to maximum within 2 seconds and then exert maximal pressure for about 3 seconds and thereafter slowly relax again. Participants were verbally encouraged to perform maximally.

For shoulder MVC and rate of force development (RFD), the child was asked to lie on a mattress in a supine position. The dominant shoulder was then positioned in external rotation and abduction, while the elbow was stretched to position the back of the wrist on the pad. The participant was instructed to press as fast and as forcefully as possible in the direction of abduction. A 30-second rest was allowed between each attempt. For both the neck and shoulder test, a minimum of three attempts was given. If the third attempt was $>5 \%$ of the second or first, an extra attempt was given, though no more than five.

5. Aerobic power was determined by a Monark Ergomedic 939E PC bike (Monark Exercise AB, Stockholm, Sweden) using a submaximal Åstrand test procedure and nomogram/accompanying tables for predicting maximal oxygen uptake $1 \cdot \min ^{-1}, V_{2_{\max }}{ }^{32}$ Heart rate was monitored using an adjustable Polar pulse belt (ProTerapi A/S, Brøndby, Denmark) and recorded continuously on a computer.

6. The number of children receiving a supply of vitamin D and/or psychologist counseling was noted.

To avoid withholding any information relevant for the child's health, the child and parents were informed about the results of the TTS and the aerobic power test by the researcher responsible. A test-retest study by Tornoe et $\mathrm{al}^{33}$ contains a detailed description of test procedures with analyses of repeatability and variability. 


\section{Allocation and interventions}

This study was a blinded block-randomized controlled trial with computer-generated allocation in blocks of ten, administered by a secretary, to place participants into one of two intervention groups, A and B. Both interventions were based on short, defined education courses of 10 weeks home training with 3-4 sessions of supervised training or counseling, approximately 140 minutes in total for each group. One or both parents participated in the sessions. The contact nurse and an experienced pediatric physical therapist administered the interventions, which were followed by a 12 -week followup period in which home practice was advised to continue without supervision. Families were welcome to request psychological counseling after the 10 weeks intervention period, which was to be supported by an interdisciplinary team conference. A timeline is provided in Figure 2.

The physical therapist taught and supervised group A in 3-4 sessions of progressive specific strength training with a focus on the trapezius muscles with resistive tubing elastics (Thera-Band; Hygenic Corporation, Akron, Ohio, USA) and recording in a prospective diary. Training was to be conducted three times a week at home and comprised alternating four exercises two by two. The progression involved doing one set with ten repetitions and moving to three sets with ten repetitions. The tubing elastics were used in three strengths, red/niveau I, green/niveau II, and blue/niveau III, to provide progression of resistance. To determine the level of resistance, a 15 repetition maximum (RM) was used to estimate an exercise resistance equivalent $75 \%-80 \%$ of one RM. ${ }^{34}$ Focus was on warm-up exercises for the arms and practicing the exercises. Furthermore, the child was guided concerning exercise quality and breathing. The task was to conduct home exercise with the aid of parental support. The progressive strength training was based on research and recommendations in the American Academy of Pediatrics, Committee on Sports Medicine and Fitness, policy statement for pediatric training, ${ }^{35}$ Faigenbaum et $\mathrm{al}^{36,37}$ and Andersen et al. ${ }^{38}$ Figure 3 provides an illustration of the exercises. During the 10 weeks of intervention, group A did not receive any other counseling. Compliance and continuity with the training schedule was secured by carrying out intermediate checks of the training diary and discussion with the child and parents.

After the 10 weeks of training, the child and family had a single counseling session with the nurse to avoid withholding help for the family.

Group B was provided with need-based counseling based on recommendations for multidisciplinary headache management. ${ }^{39}$ Group B, as an established and evidenced intervention, was the control group, in accordance with international guidelines..$^{15}$ The interdisciplinary intervention has been proven to be effective in the treatment of children in the clinic. ${ }^{40}$ The intervention comprised one session with the nurse and two sessions with the physical therapist. The focus was on a motivational dialogue following a checklist to encourage the child and parents to practice self-care through lifestyle changes and physical awareness. The aim was to enhance the child's physical health and well-being at home and at school. The child, with parental support, was encouraged to practice and exercise at home. Table 1 provides a checklist of the topics the nurse and physical therapist used during counseling.

\section{Statistical analyses}

The power analysis for this study was based on preliminary data from a case-control study and was calculated as follows: two groups of 23 participants were calculated from a mean headache frequency for girls at 20 days (SD 9.6), a significance level of $5 \%$, a power (1- $\beta$ ) at $80 \%$ and an expected difference at $40 \%$. In order not to lose power, subgroup analyses of episodic and chronic TTH were avoided.

A blinded statistician conducted the statistical analysis. Descriptive statistics were used to describe the data's central tendencies, dispersal, and trends. Mean, median, standard deviation, range, and frequency were used as appropriate. The distribution of data was examined by means of normal probability plots and Kolmogorov-Smirnov test.

\begin{tabular}{|c|c|c|}
\hline $\begin{array}{l}\text { First diagnostic visit } \\
\text { Physician and nurse. } \\
\text { Randomization }\end{array}$ & $\begin{array}{l}10 \text { weeks of intervention } \\
A \text { or } B\end{array}$ & $\begin{array}{l}\text { A: One nurse counseling } \\
12 \text { weeks home practice } \\
\text { Eventually counseling } \\
\text { by psychologist }\end{array}$ \\
\hline Test 1 & Test 2 & Test 3 \\
\hline Physician & \multicolumn{2}{|c|}{ rollow-up } \\
\hline
\end{tabular}

Figure 2 Timeline over the project period from the first diagnostic visit to test 3 .

Note: Ten weeks of intervention with either specific strength training (A) or counseling (B) followed by 12 weeks of continued home practice. 

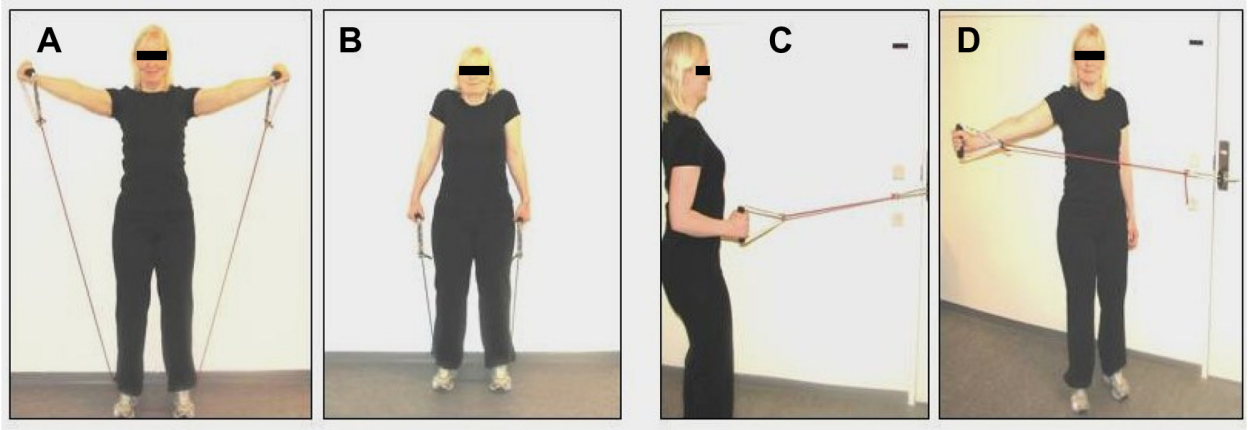

Figure 3 Four resistive exercises with tubing elastics focusing on the trapezius muscles (A-D).

For all primary and secondary variables, the difference between the two intervention groups at baseline was examined by statistical tests. Headache frequency and headache duration were analyzed as binomial counts (count parameter equaled 28 days and 24 hours, respectively) using generalized linear models. Headache intensity, peak data, TTS, and oxygen uptake were analyzed using two-sample $t$-test. Headache at test (yes/no) was analyzed by Pearson's chi-square test.

To investigate whether there was an effect of the intervention and if the effect was different after 10 weeks of intervention and after a further 12 weeks of home practice, the models included time and the interaction between time and intervention. Headache frequency, headache duration, and headache at test were analyzed by use of a repeated measurement analysis for binominal counts. We accounted for interindividual subject variation by including a random subject level. The GLIMMIX procedure by SAS 9.2 was used. The rest of the variables were analyzed by linear mixed models for repeated measurements by use of the MIXED procedure by SAS 9.2. For the primary variables, an analysis based on intention-to-treat, with the last observation carried forward, was also performed.

Results were adjusted for age and BMI. Vitamin D supplementation and counseling by psychologist were analyzed as additional explanatory variables, although the material was too small to fully adjust for four variables. Effect size was described and presented as the odds ratio (OR) $(95 \%$ confidence interval [CI]) of having headache on a random day. For all tests, the level of significance used was $5 \%$.

\section{Results}

\section{Participants}

Table 2 presents anthropometric and headache characteristics at baseline in the two intervention groups with data of

Table I Checklist with counseling topics for nurse and physical therapist

\begin{tabular}{lll}
\hline Areas & Contact nurse & Physical therapist \\
\hline Headache calendar & $\times$ & $\times$ \\
Liquids & $\times$ & $\times$ (food and \\
Food & $\times$ & exercise) \\
Sleep & $\times$ & $\times$ \\
Leisure time and hobbies & $\times$ & $\times$ \\
Physical activity & $\times$ & $\times$ \\
Screen habits and sedentary lifestyle & $\times$ & \\
Smoking & $\times$ & $\times$ \\
Physical examination & & $\times$ \\
How to exercise or use relaxation techniques & & $\times$ \\
Ergonomics & & \\
Family and school & $\times$ & \\
Potential stress factors & $\times$ & \\
Teeth, eyes, ears, nose, throat & $\times$ & \\
Blood test results and medication & $\times$ & $\times$ \\
Motivation/readiness to change & $\times$ & $\times$ \\
Confirming agreements & $\times$ & \\
\hline
\end{tabular}


Table 2 Baseline characteristics of participants

\begin{tabular}{|c|c|c|c|c|c|c|c|}
\hline Group/variable & Age in years & Weight in kg & Height in $\mathrm{cm}$ & BMI weight/height ${ }^{2}$ & $\begin{array}{l}\text { HA intensity } \\
\text { VAS }\end{array}$ & $\begin{array}{l}\text { HA frequencyl } \\
28 \text { days }\end{array}$ & $\begin{array}{l}\text { HA duration/ } \\
24 \text { hours }\end{array}$ \\
\hline Means (SD) & & & & & & Median (I-3 qrt & \\
\hline Group A & I3.4 (2.0) & $48.5(9.3)$ & I56.6 (9.0) & $19.7(3.1)$ & $4.5(1.5)$ & $22(13.5-28.0)$ & $8.0(4 . \mid-13.8)$ \\
\hline Group B & | 3.3 (I.7) & $49.1(9.8)$ & |58.| (9.0) & $19.5(2.9)$ & $4.5(1.7)$ & $24(\mid 1.0-28.0)$ & $9.3(3.7-24.0)$ \\
\hline
\end{tabular}

Abbreviations: BMI, body mass index; HA, headache; qrt, quartiles. SD, standard deviation; VAS, visual analog scale.

headache frequency, headache intensity, headache duration, age, weight, height, and BMI.

Table 3 presents mean HRQOL and disability for the pooled sample. Ninety-two percent of the participants at baseline reported mild to severe disability. Baseline characteristics and HRQOL identified deficits in the areas of physical, emotional, and school functioning. In comparison with healthy child reports from Varni et al. ${ }^{24}$ At a 2-year follow-up seven families were, for various reasons, no longer available. Twenty out of 30 potential responders (equivalent to 67\%) returned the questionnaires and were equally distributed between group A and B. One girl had moved from home, so one parental report was missing. Table 4 presents HRQOL characteristics at the 2-year follow-up. Fifty-five percent now report little to none disability, and $45 \%$ report mild to severe disability. Marked improvements are predominant in the area of physical functioning, school functioning, and total score.

Participants and dropouts at baseline, after 10 weeks of intervention, and after 12 weeks of home practice are presented in the results in Table 5. The reasons for dropouts were related to either perceived lack of time or lack of motivation. Six participants dropped out of the interdisciplinary intervention group and four out of the specific strength training group. Five girls in group A and six in group B received a vitamin D supplementation due to low levels of vitamin D on the baseline blood tests. One girl from group A visited the psychologist during the last 12-week home practice period as did five girls from group B.

In the two groups $\mathrm{A}$ and $\mathrm{B}, 42 \%$ and $44 \%$, respectively, had no headache at baseline test, and there were no significant differences over time and between groups. The mean VAS score at baseline test was 1.6 (SD 2.0) for group A and 2.2 (SD 2.6) for group B. No significant differences over time and between interventions were identified.

\section{Outcomes of primary variables}

There was a statistically significant effect on headache frequency and duration for both interventions without any significant interactions between time and interventions. For both interventions, the effect on headache frequency was statistically significant after 10 weeks of intervention $(P=0.001)$ and after 12 weeks of home practice $(P=0.001)$. The effect on duration was likewise significant $(P=0.022)$, while the effect on intensity was not significant for either groups. Figure 4 shows a line graph of treatment effect on headache frequency and duration. The results from intention-to-treat analyses were identical to the per protocol analyses. Table 5 lists all of these results.

Table 3 Baseline health-related quality of life and disability

\begin{tabular}{|c|c|c|c|}
\hline PedsQL (higher scores are better) & $\mathbf{N}=37$ girls & Child report & Proxy report \\
\hline Physical functioning & & $70.2(14.2)$ & $71.9(13.8)$ \\
\hline Emotional functioning & & $72.4(16.3)$ & $72.0(15.8)$ \\
\hline Social functioning & & $90.9(10.0)$ & $89.7(11.3)$ \\
\hline School functioning & & $64.7(17.0)$ & $70.1(16.8)$ \\
\hline Overall psychosocial functioning & & $76.0(11.8)$ & $77.3(11.2)$ \\
\hline Total score & & $74.6(10.6)$ & $75.9(10.4)$ \\
\hline PedMIDAS & $N=36$ girls & $\%$ & \\
\hline Little to none $(0-10)$ & 3 & 8.3 & \\
\hline Mild (I I-30) & 15 & 41.7 & \\
\hline Moderate $(3 \mid-50)$ & 7 & 19.4 & \\
\hline Severe $(5 I+)$ & 11 & 30.6 & \\
\hline
\end{tabular}

Notes: Values in table are given in means (SD).

Abbreviations: PedMIDAS, Pediatric Migraine Disability Assessment; PedsQL, Pediatric Quality of Life Inventory; SD, standard deviation. 
Table 4 Two-year follow-up on health related quality of life and disability

\begin{tabular}{|c|c|c|c|c|c|c|c|}
\hline $\begin{array}{l}\text { PedsQL (higher scores } \\
\text { are better) }\end{array}$ & & $\begin{array}{l}\text { Child report, } \\
N=20 \text { girls }\end{array}$ & $\begin{array}{l}P \text {-value of } \\
\text { paired diff. } \\
\text { to baseline }\end{array}$ & $95 \% \mathrm{Cl}$ & $\begin{array}{l}\text { Proxy report, } \\
\mathrm{N}=19\end{array}$ & $\begin{array}{l}P \text {-value of } \\
\text { paired diff. } \\
\text { to baseline }\end{array}$ & $95 \% \mathrm{Cl}$ \\
\hline Physical functioning & & $78.9(18.2)$ & 0.077 & $(-16.5$ to 0.9$)$ & $83.2(16.3)$ & $0.049 *$ & $(-20.3$ to -0.1$)$ \\
\hline Emotional functioning & & $76.3(16.9)$ & 0.23 & $(-12.1$ to 3.1$)$ & 75.5 (19.9) & 0.52 & $(-11.0$ to 5.8$)$ \\
\hline Social functioning & & $95.0(9.9)$ & 0.38 & $(-9.1$ to 3.6$)$ & $92.4(12.9)$ & 0.59 & $(-11.9$ to 7.0$)$ \\
\hline School functioning & & $73.0(17.3)$ & 0.078 & $(-17.5$ to 1.0$)$ & $85.0(15.1)$ & $0.047^{*}$ & $(-20.5$ to -0.2$)$ \\
\hline $\begin{array}{l}\text { Overall psychosocial } \\
\text { functioning }\end{array}$ & & $81.4(12.5)$ & 0.11 & $(-11.5$ to 1.3$)$ & $84.3(13.6)$ & 0.19 & $(-13.4$ to 2.9$)$ \\
\hline Total score & & $80.8(13.4)$ & $0.016^{*}$ & $(-16.4$ to -1.9$)$ & $84.0(14.0)$ & $0.032 *$ & $(-19.7$ to -1.0$)$ \\
\hline PedMIDAS & $N=20$ girls & $\%$ & & & & & \\
\hline Little to none $(0-10)$ & 11 & 55.0 & & & & & \\
\hline Mild (I I-30) & 3 & 15.0 & & & & & \\
\hline Moderate $(3 \mid-50)$ & I & 5.0 & & & & & \\
\hline Severe $(5 I+)$ & 5 & 25.0 & & & & & \\
\hline
\end{tabular}

Notes: $P$-values for paired differences (diff.) to baseline with $95 \% \mathrm{Cl}$, *significance level $\leq 0.05$. Values in table are presented as mean (SD).

Abbreviations: PedsQL ${ }^{\mathrm{TM}}$, Pediatric Quality of Life Inventory ${ }^{\mathrm{TM}}$; PedMIDAS, Pediatric Migraine Disability Assessment; CI, confidence interval.

The odds of having headache on a random day decreased for group A during 10 weeks of intervention by $0.68(0.47-$ $0.99)(\mathrm{OR}[95 \% \mathrm{CI}])$ and by $0.64(0.44-0.93)$ after 12 weeks of home practice. For group B, the odds decreased by 0.62 (0.44-0.89) (OR [95\% CI]) during 10 weeks of intervention and by $0.66(0.45-0.95)$ after 12 weeks of home practice. As the interaction between interventions and time was not statistically significant, the pooled OR after 10 weeks of intervention was $0.65(0.50-0.84)(\mathrm{OR}[95 \% \mathrm{CI}])$ and at the same level after 12 weeks of home practice. Over the 22 weeks, $33 \%$ of the girls had an improvement percent above $30 \%$; group A 6/20 girls, group B 7/19 girls. Twenty six percent improved above $50 \%$, specifically, $4 / 20$ girls in the A group and 6/19 girls in the B group.
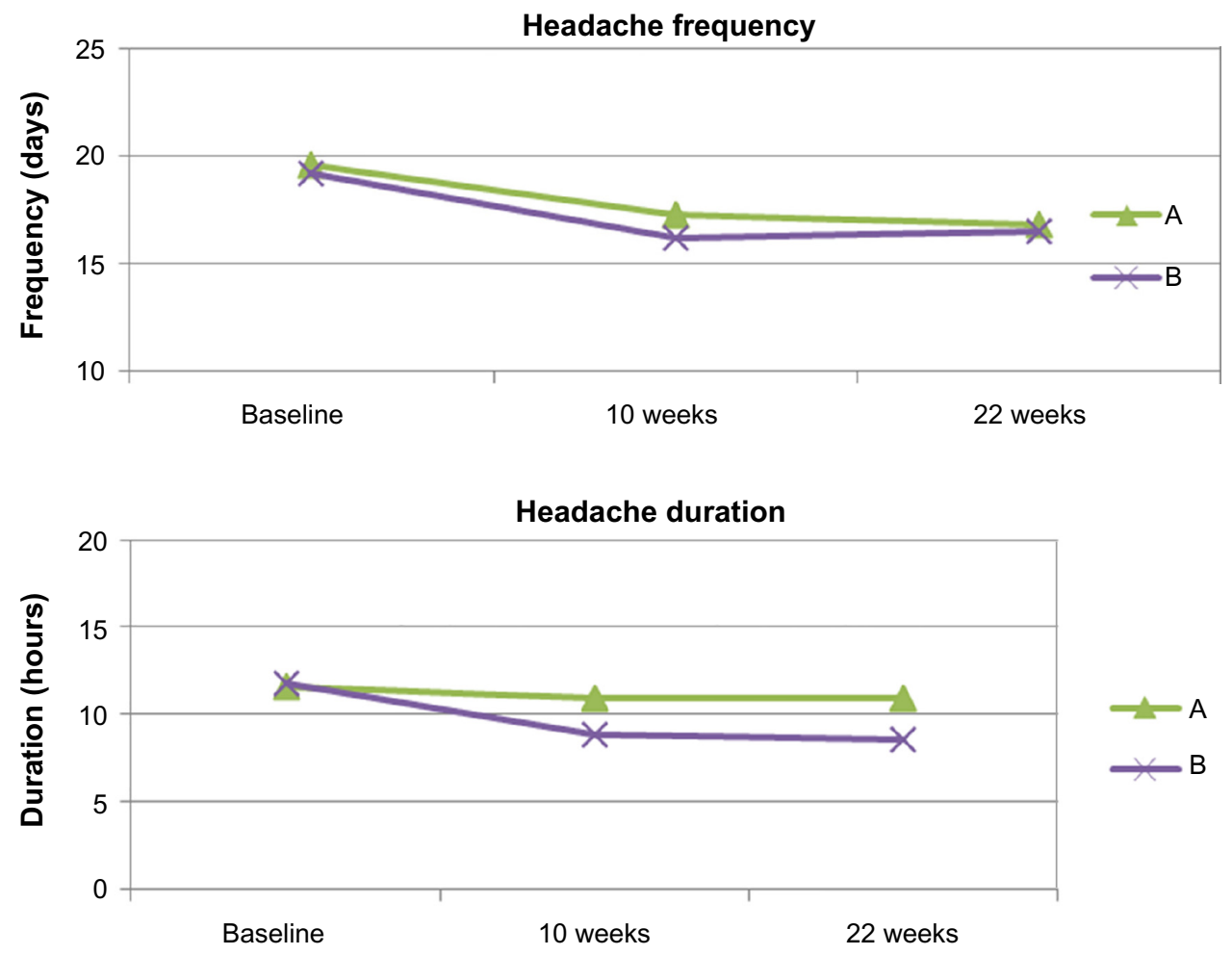

Figure 4 The effects from intervention $A$ and $B$ on headache frequency and duration over 22 weeks, adjusted for age and BMI. Abbreviation: BMI, body mass index. 







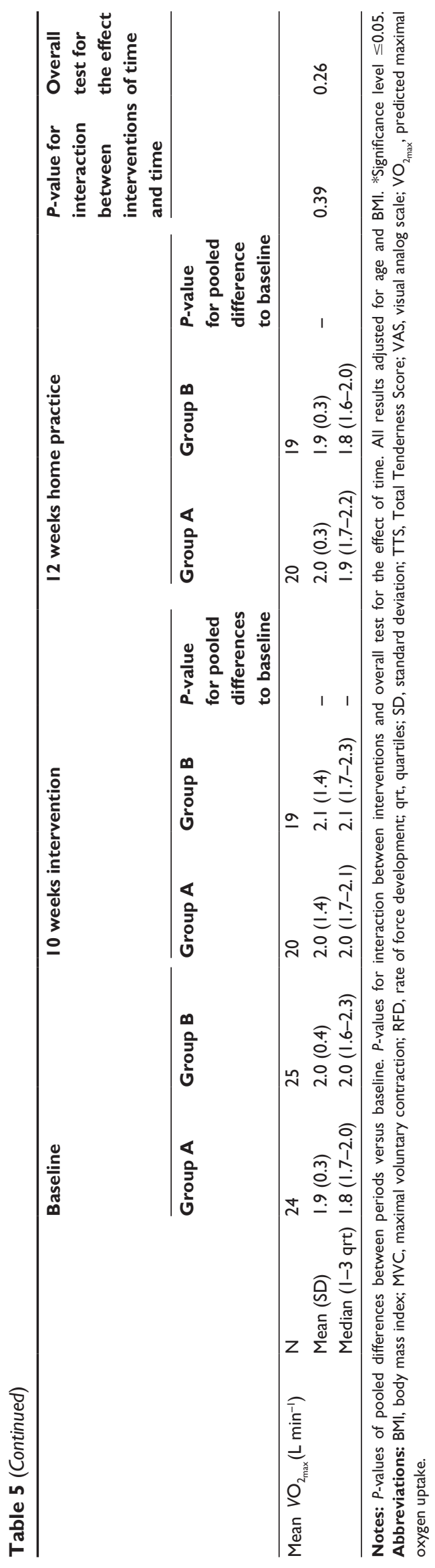

\section{Outcomes of secondary variables}

The strength training compliance was very good and all participants managed to train the entire 10 weeks as scheduled. Eighteen girls managed to progress to resistance level II by the beginning of week 5. Two of these girls, furthermore, managed to progress to resistance level III by the beginning of week 8 .

Over the 22 weeks, peak shoulder MVC increased $\geq 10 \%$ in 5/20 girls in the A group and in 2/19 girls in the B group. Four out of twenty in the A group had increased shoulder MVC $\geq 20 \%$, while none in the B group had increased shoulder MVC $\geq 20 \%$. No significant changes were found for groups.

There was a highly significant reduction in neck extension MVC from both interventions after 10 weeks of intervention $(P<0.001)$ and after 12 weeks of home practice $(P<0.001)$. There was also a significant reduction in peak neck flexion MVC for both interventions $(P=0.016)$. The cervicothoracic ratio between neck extension/neck flexion decreased over the 22 weeks from 1.9 to 1.7 for both groups.

Predicted $V \mathrm{O}_{2_{\max }}$ increased $\geq 5 \%$ in $8 / 20$ girls and $\geq 10 \%$ in 5/20 girls in the A group. In the B group, 6/19 girls had increased $V \mathrm{O}_{2_{\max }} \geq 5 \%$ and $3 / 19$ girls had increased $V \mathrm{O}_{2_{\max }}$ $\geq 10 \%$. In the $\mathrm{A}$ group, $4 / 20$ had increased oxygen uptake $\geq 15 \%$ as did $1 / 19$ in the $\mathrm{B}$ group. In the $\mathrm{A}$ group, $50 \%$ of those girls with a headache reduction of $\geq 30 \%$ had an increase in $V \mathrm{O}_{2_{\max }}>5 \%$. For the $\mathrm{B}$ group this was the case for $29 \%$.

TTS increased significantly $(P=0.001)$ for both groups. The change was within the coefficient of variation between test and retest reported by Tornoe et al. ${ }^{33}$

\section{Discussion}

The participants in this study reported deficits at baseline in HRQOL in physical, emotional, and school functioning areas, with school functioning obtaining the lowest score. This corresponds with a study by Kaczynski et $\mathrm{al}^{41}$ at an American tertiary headache clinic, reporting that headache associated with impaired school functioning for children with TTH. ${ }^{41}$ Kaczynski et al ${ }^{41}$ also report that children with TTH were more likely to choose passive coping strategies, such as withdrawal and nonparticipation. Another aspect they reported was that school difficulties were associated with a protective parental strategy. These results highlight the importance of examining coping strategies, family dynamics, and promoting self-active strategies. Our study documents that for the pooled sample, HRQOL improvements are maintained at the 2-year follow-up, in particular in physical functioning, 
school functioning, and total score. A higher percentage of girls now report little to none disability.

One of our previous studies indicated a statistically significant association between headache and reduced strength of neck-shoulder muscles and aerobic power, combined with increased pericranial tenderness, which supports the perceived deficits in physical health. ${ }^{13}$ We hypothesized that strength training of the shoulder muscles, especially the trapezius descendens, would enhance the girl's physical capability as an active coping strategy and thus provide a reduction in headache frequency. We measured health-related outcomes such as muscle strength and predicted $V \mathrm{O}_{2_{\max }}$, as well as headache.

The results from this study showed a statistically significant and clinically important reduction in headache frequency and duration due to strength training and interdisciplinary counseling. Both groups also seemed to benefit from exercising or body awareness, with a significant and not anticipated reduction in neck extension MVC and neck extension/ flexion ratio. The reduction indicates a positive change in muscle balance over the neck. Over the 22 weeks, the ratio decreased from 1.9 to 1.7 , pointing toward a possible trend that adjustment of muscle balance precedes strength gains. Cervicothoracic neck extension/flexion ratio is reported to be stable over years and between sexes and is reported at a level of $1.7-1.8^{42,43}$ in adults. In our case-control study, 41 healthy girls had a neck extension/flexion ratio at 1.8.

Faigenbaum et $\mathrm{a}^{44}$ underscore that children, due to sedentary lifestyles, may, from a young age, not develop adequate muscle strength and motor performance skills and that a deficit in muscular fitness might affect outcomes of strength training. We have not examined asymptomatic prerequisite motor skills, but based on the results we might hypothesize that the first learning outcome these girls accomplished from training was adjusting muscle balance.

The compliance with the moderate strength training program we piloted was good, and we can now conclude that it has a potential to provide important changes in physical capability both in terms of adjusting muscle balance and enhancing shoulder strength and $V \mathrm{O}_{2_{\max }}$, leading to headache reduction and health improvements. The exercise volume and intensity versus exercise variation should be considered in order to keep a stable weekly volume. Further research is still needed to examine the outcomes that children, boys and girls with TTH, gain from different intensities and energy expenditures of exercising. Also, the relationship between predicted $V \mathrm{O}_{2_{\max }}$ and TTH in girls needs further research.
Results from a study with adults with TTH by Söderberg et $a{ }^{10}$ showed significant effects on headache frequency from physical training. Training comprised ten supervised sessions with strength exercises comprising $3 \times 35$ repetitions of five exercises, with each session commencing with 10 minutes of warm-up on an ergometer bicycle. ${ }^{10}$ The exercise volume was higher than that used in the present study, and the amount of repetitions would probably not be suitable for children.

Counseling did result in both headache reduction and adjustments of muscle balance. Although the results achieved in muscle strength and aerobic power were minor, counseling also included mutual agreements of how to enhance the girl's level of physical activity.

None of the groups showed reductions in pericranial tenderness, suggesting that the girl's myofascial pain sensibility did not alter over a period of 6 months. The significant worsening of pericranial tenderness was not anticipated and is interpreted as being due to a rather large coefficient of variation, ${ }^{33}$ which needs to be further studied. As enhanced pericranial tenderness is seen as a consequence of frequent or chronic $\mathrm{TTH},{ }^{45}$ the lack of reduction in tenderness might indicate that expectations of recovery from a chronic headache situation have a prolonged perspective.

Dropouts were explained by a perceived lack of either time and/or motivation. To limit the number of sessions and at the same time reach the child's motivation to choose active coping strategies, innovative learning strategies should be considered. Digital learning and support combined with social events for the child and family might support an interactive learning situation. Physical therapists can work to find new ways of encouraging the child to do physical exercise with, and not despite, electronic devices to counteract a sedentary lifestyle.

This study did not examine knowledge improvements or motivation for change/barriers for change at an individual level. Baker et $\mathrm{al}^{46}$ recommended identifying barriers for change in interventions at both an organizational and individual level, although evidence of the effect of identifying barriers is not yet clear. Consequently, more research is needed that examines the needs of contemporary families and that explores the barriers parents and children face in order to reinvent social and interactive physical behaviors that benefit the child's health and well-being.

\section{Limitations and comments}

The 1989 UN Convention on the Rights of the Child states that "the best interests of children must be the primary concern in making decisions that may affect them". This was our 
main concern when setting up the study and meant that we did not establish a control group without treatment or a placebo treatment. We dealt with interventions as defined by the complexity of involving a variety of health-care professionals at various organizational levels with different behaviors. The study targeted families with an array of behavioral cultures, expectations, and different degrees of compliance. We were able to control the duration of confrontation and the amount of homework. In complex interventions, we are challenged by the difficulty of isolating the "active ingredients" of an intervention and have therefore focused on who accomplished what. Some of the strengths of this study include the effort put into controlling for influencing factors, the well-examined test methodology, and the blinded statistical analyses. The fact that we only managed to include girls turned out to be a statistical strength avoiding subgroup analyses. We did not examine the situation of the contemporary family to explore the knowledge gained or the process of change, but these aspects are needed in future research involving these children and their parents.

\section{Conclusions and implications for practice}

Both educating girls with TTH in a moderate strength training program for a period of 10 weeks and doing need-based motivational counseling for lifestyle changes have a significant effect on headache frequency and duration with no significant between-group difference. The 2-year follow-up on HRQOL revealed consistent improvements over time. The majority of the girls reported little to none disability, with a total score approaching normative data. The results indicate that both physical health and HRQOL can be influenced significantly by physical exercise and nurse counseling.

However, we need to know more about how the dosing and energy expenditure in exercising affects both girls and boys with TTH. Face-to-face supervision of the exercise is recommended to ensure its quality and to prevent adverse effects.

Imparting knowledge about healthy lifestyles and active coping strategies, such as physical exercise, supported by digital learning and support, social activities, and events, is a possible option for limiting the amount of sessions necessary while simultaneously supporting interactive learning.

\section{Acknowledgments}

We would like to thank all the children and parents who took the time to participate in this study. We especially thank research lab technician Hanne Andresen, the Danish Headache Centre, Glostrup Hospital, University of Copenhagen, for conducting all the testing. We are also grateful to the, at the time, nursing and physical therapy students, Christian Tilsted, Pernille Hansen, May Bang and Marianne Villadsen, who assisted in the testing procedures. Finally, we would also like to thank Nancy Aaen, MA, for participating in the editing process.

This project was supported by Master Carpenter Jørgen Holm and Wife Elisa F. Hansen's Memorial Trust; the Beckett-Foundation; the Lundbeck Foundation; the Axel Muusfeldt's Foundation; the Dagmar Marshalls Foundation; the European Movement/V-Foundation, TrygFonden, a Danish foundation and Department of Health Sciences, Lund University.

\section{Disclosure}

The authors report no conflicts of interest in this work.

\section{References}

1. Connelly M, Bickel J. An electronic daily diary process study of stress and health behavior triggers of primary headaches in children. $J$ Pediatr Psychol. 2011;36(8):852-862.

2. Bussone G, Grazzi L, D’Amico D, Leone M, Andrasik F. Biofeedbackassisted relaxation training for young adolescents with tension-type headache: a controlled study. Cephalalgia. 1998;18(7):463-467.

3. Grazzi L, Andrasik F, D'Amico D, Leone M, Moschiano F, Bussone G. Electromyographic biofeedback-assisted relaxation training in juvenile episodic tension-type headache: clinical outcome at 3-year follow-up. Cephalalgia. 2001;21(8):798-803.

4. Tornoe B, Skov L. Computer animated relaxation therapy in children between 7 and 13 years with tension-type headache: a pilot study. Appl Psychophysiol Biofeedback. 2012;37:35-44.

5. Nestoriuc Y, Rief W, Martin A. Meta-analysis of biofeedback for tension-type headache: efficacy, specificity, and treatment moderators. J Consult Clin Psychol. 2008;76(3):379-396.

6. Gottschling S, Meyer S, Gribova I, et al. Laser acupuncture in children with headache: a double-blind, randomized, bicenter, placebo-controlled trial. Pain. 2008;137(2):405-412.

7. Andrasik F, Grazzi L, Usai S, Bussone G. Pharmacological treatment compared to behavioural treatment for juvenile tension-type headache: results at 2-year follow-up. Neurol Sci. 2007;28(Supp1 2):S235-S238.

8. Andrasik F. Behavioral treatment of headaches: extending the reach. Neurol Sci. 2012;33(Suppl 1):S127-S130.

9. Trautmann E, Kroner-Herwig B. A randomized controlled trial of Internet-based self-help training for recurrent headache in childhood and adolescence. Behav Res Ther. 2012;48(1):28-37.

10. Söderberg E, Carlsson J, Stener-Victorin E. Chronic tension-type headache treated with acupuncture, physical training and relaxation training. Between-group differences. Cephalalgia. 2006;26:1320-1329.

11. Andersen LL, Mortensen OS, Zebis MK, Jensen RH, Poulsen OM. Effect of brief daily exercise on headache among adults - secondary analysis of a randomized controlled trial. Scand J Work Environ Health. 2011;37(6):547-550.

12. WHO. WHO Global Recommendations on Physical Activity for Health. 2011. Available from: http://www.who.int/topics/physical_activity. Accessed December 31, 2015.

13. Tornoe B, Andersen LL, Skotte JH, et al. Reduced neck-shoulder muscle strength and aerobic power together with increased pericranial tenderness are associated with tension-type headache in girls: a case-control study. Cephalalgia. 2014;34(7):540-547. 
14. CONSORT Group. CONSORT-Statement. 2010. Available from: http:// www.consort-statement.org/consort-statement/. Accessed December 31, 2015.

15. Penzien DB, Andrasik F, Freidenberg BM, et al. Guidelines for trials of behavioral treatments for recurrent headache, first edition: American Headache Society Behavioral Clinical Trials Workgroup. Headache. 2005;45(Supp1 2):S110-S132.

16. Andrasik F, Powers SW, McGrath PJ. Methodological considerations in research with special populations: children and adolescents. Headache. 2005;45(5):520-525.

17. Headache Classification Committee of the International Headache Society I. The International Classification of Headache Disorders, 2nd edition. Cephalalgia. 2004;24(Suppl 1):39-41.

18. Headache Classification Committee of the International Headache Society I. The International Classification of Headache Disorders, 3rd edition (beta version). Cephalalgia. 2013;33(9):629-808.

19. Jensen R, Tassorelli C, Rossi P, et al. A basic diagnostic headache diary (BDHD) is well accepted and useful in the diagnosis of headache. a multicentre European and Latin American study. Cephalalgia. 2011;31(15):1549-1560.

20. WMA. Declaration of Helsinki. Principles for Medical Research involving Human Subjects. 2013. Available from: http://www.wma. net. Accessed December 31, 2015.

21. UN. Convention on the Rights of the Child. 1989. Available from: http:// www.unicef.org/crc. Accessed December 31, 2015.

22. Patrick J, McGrath PA, Unruh AM. Measurement and assessment of paediatric pain. Textbook of Pain. Philadelphia, PA: Elsevier; 2006; Chapter 19.

23. MPI. PedsQ1 ${ }^{\mathrm{TM}}$. Lyon, France: Mapi Research Institute. 2003. Available from: http://www.pedsql.org/pedql-liguistic-validation-guidelines.doc. Accessed January 1, 2015.

24. Varni JW, Seid M, Kurtin PS. PedsQL 4.0: reliability and validity of the Pediatric Quality of Life Inventory version 4.0 generic core scales in healthy and patient populations. Med Care. 2001;39(8):800-812.

25. Varni JW. The PedsQL ${ }^{\mathrm{TM}}$, Measurement Model for the Pediatric Quality Inventory TM. 1998-2012. Available from: http://www.pedsql.org. Accessed January 1, 2015.

26. Cincinnati Children's, Headache Centre. 2013. Available from: http:// www.cincinnatichildrens.org/service/h/headache-center/pedmidas/. Accessed January 1, 2015.

27. Hershey AD, Powers SW, Vockell AL, LeCates S, Kabbouche MA, Maynard MK. PedMIDAS: development of a questionnaire to assess disability of migraines in children. Neurology. 2001;57(11):2034-2039.

28. Grazzi L, D’Amico D, Usai S, Solari A, Bussone G. Disability in young patients suffering from primary headaches. Neurol Sci. 2004; 25(Suppl 3):S111-S112.

29. Smits-Engelsman B, Klerks M, Kirby A. Beighton score: a valid measure for generalized hypermobility in children. J Pediatr. 2011;158(1):119123, 23.e1-e4.

30. Bendtsen L, Jensen R, Jensen NK, Olesen J. Muscle palpation with controlled finger pressure: new equipment for the study of tender myofascial tissues. Pain. 1994;59(2):235-239.
31. Bendtsen L, Jensen R, Jensen NK, Olesen J. Pressure-controlled palpation: a new technique which increases the reliability of manual palpation. Cephalalgia. 1995;15(3):205-210.

32. Åstrand PO, Rodahl K, Dahl HA, Strømme SB. Textbook of Work Physiology; Physiological Bases of Exercise. 4th ed. Windsor, Canada: Human Kinetics; 2003.

33. Tornoe B, Andersen LL, Skotte JH, et al. Test-retest repeatability of strength capacity, aerobic power and pericranial tenderness of neck and shoulder muscles in children-relevant for tension-type headache. J Pain Res. 2013;6:1-9.

34. Holten O, Faugli HP. Medisinsk Treningsterapi. 2nd ed. Oslo, Norway: Universitetsforlaget; 1994.

35. McCambridge TM, Stricker PR. Strength training by children and adolescents. Pediatrics. 2008;121(4):835-840.

36. Faigenbaum AD, Loud RL, O’Connell J, Glover S, Westcott WL. Effects of different resistance training protocols on upper-body strength and endurance development in children. J Strength Cond Res. 2001;15(4):459-465.

37. Faigenbaum AD, Kraemer WJ, Blimkie CJ, et al. Youth resistance training: updated position statement paper from the national strength and conditioning association. J Strength Cond Res. 2009;23(5 Suppl):S60-S79.

38. Andersen LL, Saervoll CA, Mortensen OS, Poulsen OM, Hannerz H, Zebis MK. Effectiveness of small daily amounts of progressive resistance training for frequent neck/shoulder pain: randomised controlled trial. Pain. 2011;152(2):440-446.

39. Gaul C, Visscher CM, Bhola R, et al. Team players against headache: multidisciplinary treatment of primary headaches and medication overuse headache. J Headache Pain. 2011;12(5):511-519.

40. Soee AB, Skov L, Skovgaard LT, Thomsen LL. Headache in children: Effectiveness of multidisciplinary treatment in a tertiary paediatric headache clinic. Cephalalgia. 2013;33:1218-1228.

41. Kaczynski KJ, Claar RL, Lebel AA. Relations between pain characteristics, child and parent variables, and school functioning in adolescents with chronic headache: a comparison of tension-type headache and migraine. J Pediatr Psychol. 2013;38(4):351-364.

42. Jordan A, Mehlsen J, Bulow PM, Ostergaard K, Danneskiold-Samsoe B. Maximal isometric strength of the cervical musculature in 100 healthy volunteers. Spine (Phila Pa 1976). 1999;24(13):1343-1348.

43. Van Wyk L, Jull G, Vicenzino B, Greaves M, O'Leary S. A comparison of craniocervical and cervicothoracic muscle strength in healthy individuals. J Appl Biomech. 2010;26(4):400-406.

44. Faigenbaum AD, Lloyd RS, Myer GD. Youth resistance training: past practices, new perspectives, and future directions. Pediatr Exerc Sci. 2013;25(4):591-604.

45. Bendtsen L, Fernandez-de-la-Penas C. The role of muscles in tensiontype headache. Curr Pain Headache Rep. 2011;15(6):451-458.

46. Baker R, Camosso-Stefinovic J, Gillies C, et al. Tailored interventions to overcome identified barriers to change: effects on professional practice and and health care outcomes. Cochrane Database Syst Rev. 2010;(3):CD005470. 
Video abstract

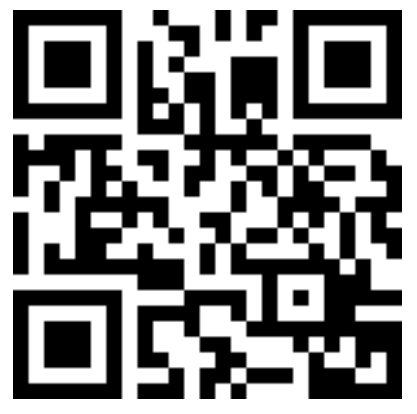

Point your SmartPhone at the code above. If you have a

QR code reader the video abstract will appear. Or use: http://youtu.be/ik6cMSZMw5I

\section{Publish your work in this journal}

The Journal of Pain Research is an international, peer-reviewed, open access, online journal that welcomes laboratory and clinical findings in the fields of pain research and the prevention and management of pain. Original research, reviews, symposium reports, hypothesis formation and commentaries are all considered for publication.
The manuscript management system is completely online and includes a very quick and fair peer-review system, which is all easy to use. Visit http://www.dovepress.com/testimonials.php to read real quotes from published authors. 